\title{
Human mesenchymal stem cells stimulate EaHy926 endothelial cell migration: combined proteomic and in vitro analysis of the influence of donor-donor variability
}

\author{
Walter MNM${ }^{1}$, Kohli $\mathrm{N}^{2}$, Khan $\mathrm{N}^{2}$, Major $\mathrm{T}^{2}$, Fuller $\mathrm{H}^{1}$, Wright $\mathrm{KT}^{1}$, Kuiper $\mathrm{JH}^{1}$, Johnson WEB ${ }^{1,2}$
}

Mesenchymal stem cells (MSCs) stimulate angiogenesis within a wound environment and this effect is mediated through paracrine interactions with the endothelial cells present. Here we report that human MSC-conditioned medium ( $n=3$ donors) significantly increased EaHy-926 endothelial cell adhesion and cell migration, but that this stimulatory effect was markedly donordependent. MALDI-TOF/TOF mass spectrometry demonstrated that whilst collagen type I and fibronectin were secreted by all of the MSC cultures, the small leucine rich proteoglycan, decorin was secreted only by the MSC culture that was least effective upon EaHy-926 cells. These individual extracellular matrix components were then tested as culture substrata. EaHy-926 cell adherence was greatest on fibronectin-coated surfaces with least adherence on decorin-coated surfaces. Scratch wound assays were used to examine cell migration. EaHy-926 cell scratch wound closure was quickest on substrates of fibronectin and slowest on decorin. However, EaHy-926 cell migration was stimulated by the addition of MSC-conditioned medium irrespective of the types of culture substrates. These data suggest that whilst the MSC secretome may generally be considered angiogenic, the composition of the secretome is variable and this variation probably contributes to donor-donor differences in activity. Hence, screening and optimizing MSC secretomes will improve the clinical effectiveness of pro-angiogenic MSC-based therapies.

Key Words: Mesenchymal stem cell, EaHy-926 Endothelial cell, Angiogenesis, Secretome, Donor variability

\section{Introduction}

Many potential therapies for severe and/or chronic wounds fail as a result of poor vasculature ${ }^{[1]}$. Hence, strategies to improve blood vessel supply into a wound bed are thought to promote wound healing. Transplantations of mesenchymal stem cells (MSCs) have shown great potential as a therapeutic agent for the treatment of a range of disorders, including wound healing, and have become the subject of numerous clinical trials $^{[2]}$. However, whilst the safety of MSC transplantation does not seem to be an issue ${ }^{[3,4]}$, the effectiveness of such treatment has exhibited considerable variability. This variation in effect is problematic when translating preclinical research into MSC-based clinical therapy.

We recently demonstrated that human MSC-conditioned medium (MSC-CM) was stimulatory to epidermal and fibroblast cell adherence and migration ${ }^{[5]}$. Other reports suggest that MSC are pro-angiogenic also through their paracrine activity on endothelial cells ${ }^{[6,7]}$. Whilst there are reports that MSC are capable of endothelial differentiation ${ }^{[8,9]}$, engraftment into new vasculature is low in vivo ${ }^{[10,11]}$. Hence, these and other studies have contributed to recent thought that the predominant regenerative activity of MSCs is due to their secretion of factors that stimulate endogenous cells at wound sites.

In this investigation, we have examined the effects of MSC$\mathrm{CM}$ on endothelial cells, using the cell line EaHy-926 as a model system ${ }^{[12]}$. We report that MSC-CM promotes endothelial cell adhesion and migration, but that these effects show considerable donor-donor variability. Further, we have identified extracellular matrix (ECM) proteins that are secreted by MSCs using MALDI/TOF-TOF mass spectrometry. We provide data to suggest that ECM composition plays a major role in the donordonor variation we have seen. These findings demonstrate proof of principle of the need to screen the MSC secretome in order to optimise the application of MSCs in the clinic.

\section{Methods}

\section{Cell culture and mass spectrometry of conditioned medium}

EaHy-926 endothelial cells were maintained in DMEM/F12 culture medium (Invitrogen, Paisley, UK) supplemented with $10 \%(\mathrm{v} / \mathrm{v})$ fetal calf serum (FCS) (Invitrogen) and $1 \%(\mathrm{v} / \mathrm{v})$ penicillin and streptomycin (Invitrogen), incubated at $37^{\circ} \mathrm{C}$ and in a humidified atmosphere containing $5 \%(\mathrm{v} / \mathrm{v}) \mathrm{CO}_{2}$. Passaging was performed at $\sim 90 \%$ confluence and cells were re-seeded at $1 \times 10^{4}$ cells $/ \mathrm{cm}^{2}$. MSCs were isolated from the iliac crest biopsies of bone marrow donors following ethical approval and with informed consent, as previously described ${ }^{[13]}$. The adherent cell population obtained was consistent with the characteristics of MSCs laid out by the International Society for Cellular Therapy (ISCT $)^{[14]}$. Conditioned medium was generated from MSC cultures of equal cell number in serum free 
conditions, using DMEM/F12 supplemented with insulin, transferrin and selenium (Invitrogen). Protein content of MSC CM was determined by MALDI-TOF/TOF mass spectrometry as previously described ${ }^{[5]}$.

\section{Characterization of MSC}

After three passages in culture, bone marrow derived cells were assessed by immunoprofiling for CD markers and by examining their differentiation potential to form osteoblasts, adipocytes and chondrocytes, by staining with alkaline phosphatase, oil red $\mathrm{O}$, and toluidine blue respectively as per the criteria established for a MSC phenotype by the ISCT ${ }^{[14]}$.

\section{Coating of culture plates}

Culture plates were coated with MSC-CM or type-I collagen, decorin, or fibronectin (all Sigma-Aldrich). Protein solutions were diluted in PBS to $0.2 \mathrm{mg} / \mathrm{ml}$ and added to each well $(50 \mu \mathrm{l}$ for 96-well plates, $500 \mu \mathrm{l}$ for 24-well plates). These were refrigerated for 24 hours before being rinsed with PBS immediately prior to use.

\section{Cell adherence/spreading}

Coated 24-well tissue culture plates were seeded with $2 \times 10^{5}$ EaHy-926 endothelial cells in DMEM/F12 supplemented with $1 \%$ penicillin/streptomycin (Sigma-Aldrich) and 1\% ITS-X (Sigma-Aldrich) and incubated for 2 hours at $37^{\circ} \mathrm{C}$ and $5 \%$ $\mathrm{CO}_{2}$ before digital images were captured (ProgRes CF, Jenoptik) and analysed using Image-J software.

\section{Scratch-wound assays}

Scratch assays were established using previously published methods $^{[5]}$, in protein-coated tissue culture plates (as described above). Cell migration was automatically captured and analysed at hourly intervals using an Incucyte ${ }^{\mathrm{TM}}$ LiveCell Imaging System (Essen Bioscience).

\section{Statistical analysis}

Data is presented as means $( \pm$ SEM). Data were tested for significance using the Mann-Whitney $U$ test. Those differences that fell within a $95 \%, 99 \%$ or $99.9 \%$ confidence interval were considered to be significant, indicated by asterisks within Figures $\left({ }^{*} p<0.05^{* *} p<0.01{ }^{* * *} p<0.001\right)$.

\section{Results}

Bone marrow cells obtained from iliac crest biopsies showed characteristics consistent with those expected of MSC (Figure 1). MSC-CM coating of culture plates resulted in the significant enhancement of the spreading of EaHy-926 endothelial cells upon the culture surface. This result was subject to a marked inter-donor variability, with conditioned media generated by both MSC-1 and MSC-3 resulting in a significantly greater degree of EaHy-926 endothelial cell spreading than that generated by MSC-2 (Figure 2a, 2b). EaHy-926 endothelial cell adherence on fibronectin coated plates was most advanced after two hours, compared to plates coated in either type I collagen or with decorin (Figure 3). On type I collagen-coated plates, the presence of MSC-CM appeared to enhance the rate of EaHy926 endothelial cell migration into scratch-wounds compared to unconditioned media (Figure 4a, left). EaHy-926 endothelial cells in MSC-CM closed scratch-wounds to a significantly greater degree than those in unconditioned media over a 12-hour time course (Figure 4b, left). Once again, the degree of this MSC-CM mediated enhancement of EaHy-926 endothelial cell migration was subject to interdonor variability. Conditioned medium generated by MSC-1 (and MSC-3) elicited a greater degree of scratch-wound closure than MSC-2 over 12 hours (Figure 4b, left).

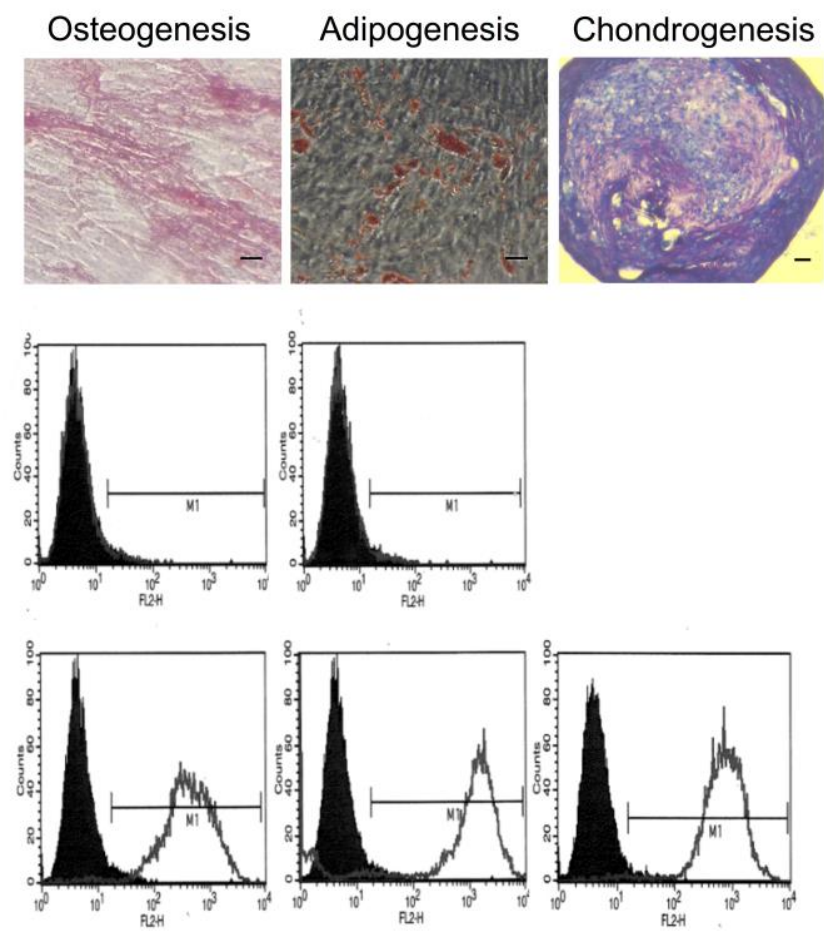

Figure 1 Cells isolated from bone marrow meet the minimum criteria for identification as MSC. Cells are immunoreactive for CD73, CD90 and CD105, whilst lacking immunoreactivity for CD14, CD34 and CD45, as shown by histograms obtained by flow cytometry, and readily differentiate to form osteoblasts, adipocytes and chondrocytes in vitro. Representative phase contrast images are shown of cells following trilineage differentiation and staining with alkaline phosphotase, oil red $\mathrm{O}$, and toluidine blue (top, left to right). Scale bars $=50 \mu \mathrm{m}$. 
a

MSC-CM
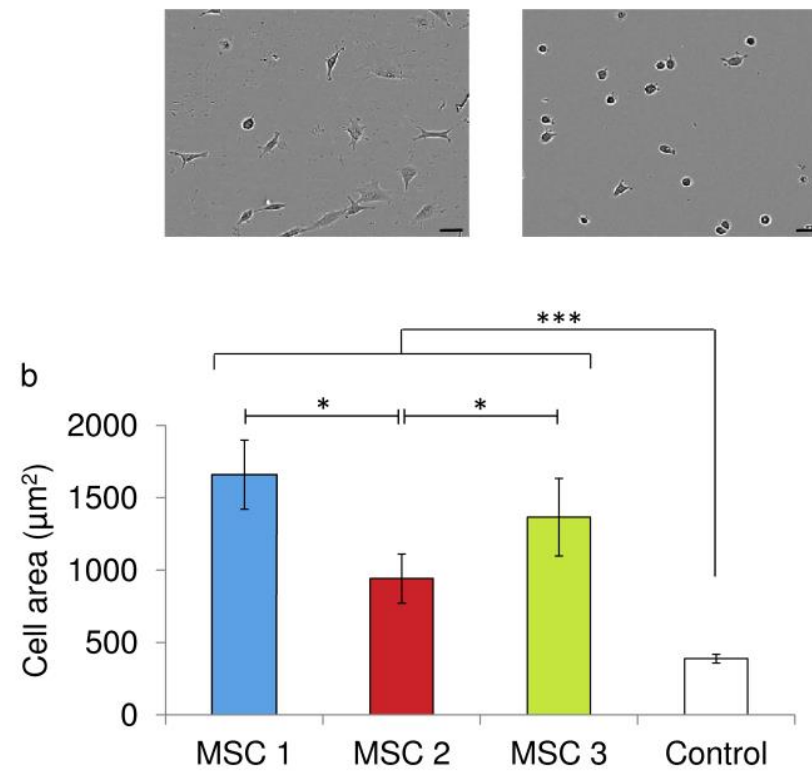

Figure 2 MSC-CM coating of culture plates influences EaHy-926 endothelial cell adherence and spreading. A: MSC-CM coating of culture plates influences EaHy-926 endothelial cell adherence and spreading. After 4 hours in culture EaHy-926 endothelial cells were observably more spread on culture plates coated with MSC-CM than on plates coated with unconditioned (control) medium. Representative phase contrast images are shown of EaHy-926 endothelial cells 4 hours post seeding. B: After 4 hours in culture the average cell area was significantly greater for EaHy-926 endothelial cells on MSC-CM coated culture plates and $389 \mu \mathrm{m} 2$ than those cells on unconditioned (control) medium coated culture plates. Data shown are means \pm SEM in relative units $\left({ }^{* * *}=p<0.001\right.$ Mann Whitney $U$ test $)$.

a

Collagen

Decorin

Fibronectin

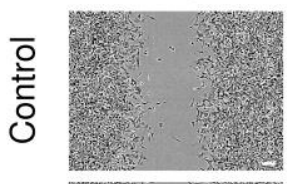

$\sum$
0
$\vdots$
$\vdots$
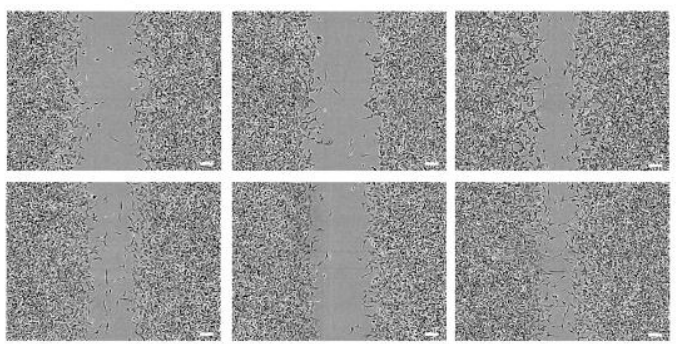

b

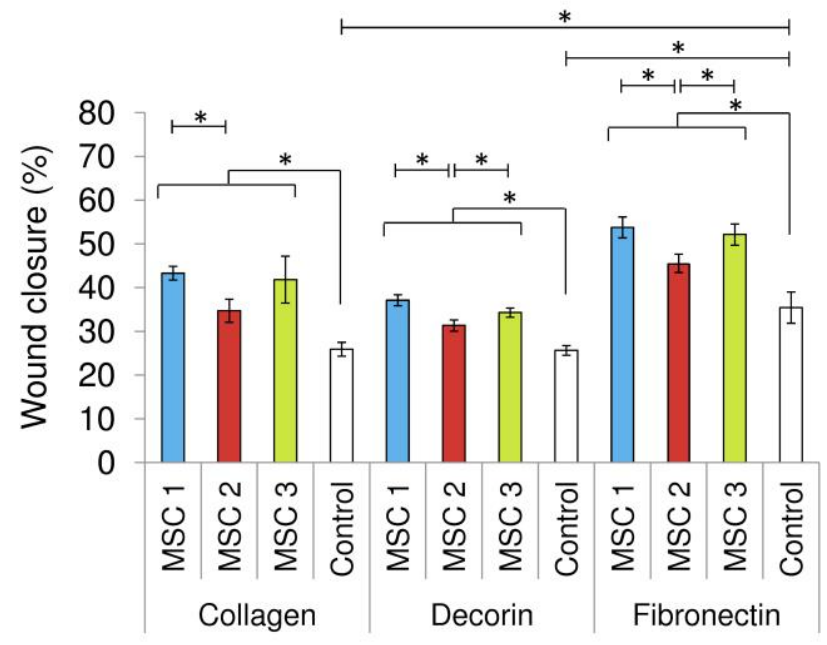

a

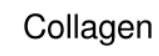

Decorin

Fibronectin
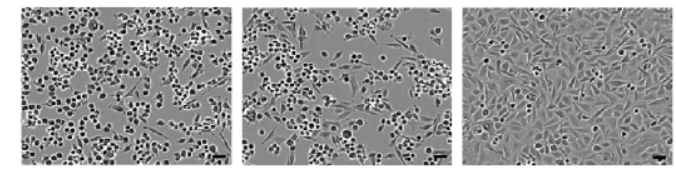

b

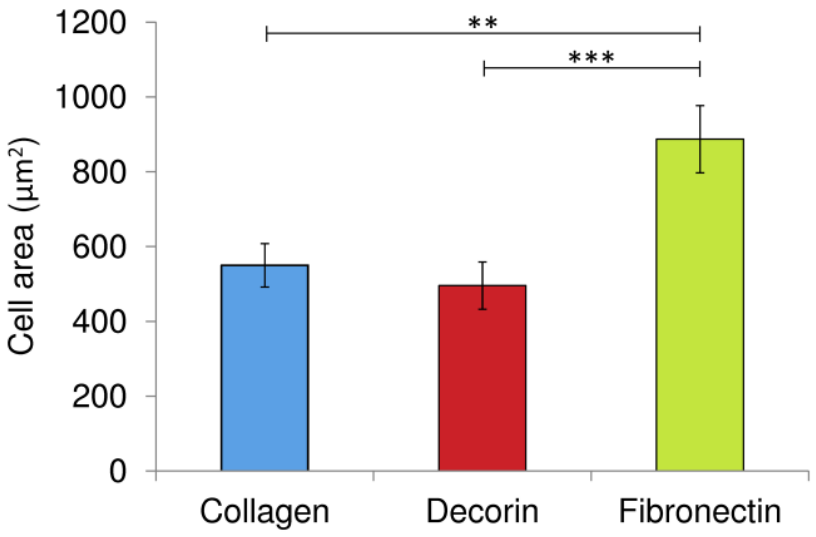

Figure 3 ECM protein coating of culture plates influences EaHy-926 endothelial cells adherence and spreading. After 4 hours in culture EaHy-926 endothelial cells were observably more spread on culture plates coated with fibronectin than on plates coated with type I collagen or decorin. Representative phase contrast images are shown of EaHy-926 endothelial 4 hours post seeding. $B:$ After 4 hours in culture the average cell area was significantly greater for EaHy926 endothelial cells on fibronectin compared to those cells on either type collagen or decorin. Data shown are means \pm SEM in relative units $\left(^{* *}=p<0.01\right.$, ${ }^{* * *}=p<0.001$, Mann Whitney $U$ test).
Figure 4 EaHy-926 endothelial cells closed scratch wounds faster in MSC-CM than in unconditioned medium on type I collagen, fibronectin, and decorin coated culture plates. A: EaHy-926 cells on fibronectin coated culture plates closed scratch wounds significantly faster than those on either type I collagen or decorin. Representative phase contrast images are shown of EaHy-926 scratch assays 12 hours post scratching. B: After 12 hours EaHy-926 endothelial cells in MSC-CM had closed scratch wounds by a significantly greater degree than those in unconditioned control medium. 12 hours post-scratching, EaHy-926 endothelial cells on plates coated fibronectin had closed scratch wounds by a significantly greater degree than those on either type I collagen or decorin. On fibronectin and decorin, medium conditioned by MSC-2 was associated with significantly reduced scratch closure compared to either MSC-1 or MSC-3. On type one collagen, medium conditioned by MSC-2 was associated with significantly reduced scratch closure compared to MSC-1. Data shown are means \pm SEM. $~^{*}{ }^{*}=p<0.05$ by Mann Whitney U test). 
These MSC-CM were examined by MALDI/TOF/TOF mass spectrometry. All three were found to contain fibronectin, collagen type I, collagen type VI, and lumican, whilst cartilage oligomeric matrix protein (COMP) and SPARC were present in two out of three MSC-CM and laminin, decorin, heparan sulphate proteoglycan (HSPG) and IGFBP-1 were each only observed in one MSC-CM (Table 1). Of these, decorin, along with HSPG were only present in medium conditioned using MSC-2. Hence, not only was there clear inter-donor variability in the ECM components of the MSC secretome, but the presence of these proteoglycans seemed to be associated with a reduction in the efficacy of MSC-CM.

When type I collagen, decorin and fibronectin were used as culture substrata, the degree of EaHy-926 endothelial cell spreading appeared to be similar upon both type I collagen and decorin and greatly enhanced upon fibronectin (Figure $2 a, 2 b)$.

Similarly, scratch-wound closure by EaHy-926 endothelial cells in unconditioned media appeared to be similar upon type I collagen and decorin, but markedly greater upon fibronectin (Figure $4 a, 4 b$ ). In the presence of each ECM substrate the presence of MSC-CM resulted in significantly enhanced scratch wound closure compared to unconditioned media (Figure 4b). As seen previously upon type I collagen coated culture plates, the degree of closure upon both decorin and fibronectin coated plates was either significantly or near significantly ( $p=0.057$ by Mann Whitney $U$ test) less in the presence of medium conditioned by MSC-2, compared to medium conditioned by either MSC-1 or MSC-3 (Figure $4 b)$.

Table 1: EXTRACELLULAR MATRIX PROTEINS DETECTED IN MSC CONDITIONED MEDIUM USING (MALDI-TOF/TOF) MASS SPECTROMETRY

MSC-CM 1

Fibronectin

Type I Collagen

Type VI Collagen

Laminin

COMP

Lumican

$-$

$-$

SPARC

IGFBP-1
MSC-CM 2

Fibronectin

Type I Collagen

Type VI Collagen

Lumican

Decorin

HSPG

SPARC
MSC-CM 3

Fibronectin

Type I Collagen

Type VI Collagen

COMP

Lumican

$-$

Mass spectrometry of MSC-CM from 3 separate donors. MALDI-TOF/TOF mass spectrometry of MSC-CM detected variable protein content between media conditioned by MSC from three different patient donors.

\section{Discussion}

We have previously shown that MSC-CM promotes the migration of skin cells in a wound healing model, and identified numerous potentially beneficial factors that may contribute to this effect. In vivo wound healing is, however, a complex process influenced by a host of cellular events, including angiogenesis. If MSC can stimulate endothelial cells as suggested here and elsewhere ${ }^{[7]}$ this supports their potential use in the treatment of cutaneous wounds.

In these experiments, MSC-CM was found to be stimulatory to endothelial cell migration in vitro. This is similar to previous studies in which MSC-CM has been shown to stimulate angiogenesis ${ }^{[7]}$, supporting the investigation of MSC-CM as a pro-angiogenic agent. Although it is possible for proliferation of EaHy-926 endothelial cells to have contributed somewhat to the closure of the scratch wounds, these scratch assay experiments were performed over the course of 12 hours. The reported doubling time for these cells is over 25 hours $^{[15]}$. To significantly affect the rate of scratch wound closure, those cells at the leading edge of the scratch margins would be required to undergo repeated doublings, and this is unlikely to have had a major influence on scratch wound closure over the time course of these studies. 
Mass spectrometry of MSC-CM revealed numerous factors (including fibronectin and collagen) in medium conditioned by each of the three MSC examined and some, including laminin and decorin, in one or two but not all three of the MSC-CM samples. Of these ECM components, fibronectin, collagen and laminin are known to promote or support angiogenesis ${ }^{[16]}$. Unusually, in these experiments collagen did not seem to induce any observable cell response when compared to decorin. This result may be elucidated through further study. Fibronectin and collagen contain protein motifs are known to mediate angiogenesis by integrin receptor signaling in vivo and in vitro ${ }^{[17-19]}$. Laminin peptides have also been shown to be pro-angiogenic ${ }^{[20]}$. Conversely decorin and lumican have been shown to inhibit angiogenesis. Decorin inhibits endothelial cell migration and tubule formation in vitro [21] and inhibits the pro-angiogenic effects of VEGF ${ }^{[22]}$. Lumican interferes with $\alpha 2 \beta 1$ receptor activity and inhibits angiogenesis both in vitro and in vivo ${ }^{[23,24]}$. Whilst lumican was present in each of the MSC-CM used in these investigations, decorin was only found within the MSC-CM that consistently showed significantly less enhancement of EaHy-926 endothelial cell migration. As the method (MALDITOF/TOF mass spectrometry) used to detect these protein components within MSC-CM was not quantitative, it was not possible to determine whether differences in concentrations of each ECM component were related to efficacy of the conditioned media.

MSC-CM coating of culture plates enhanced EaHy-926 endothelial cell adherence, as did coating with fibronectin. Cell adherence to these substrata was examined in an indirect fashion, by assessing the average area of cells in the immediate-early period after seeding. As cells settle upon a permissive substrate they spread out from the rounded morphology observed in suspension to adopt a flattened morphology that is usually seen in vitro in adherent cell populations. After prolonged periods of time, cells in culture, including endothelial cells, synthesize matrix molecules that may also promote cell adhesion, potentially masking the initial effects of the original substrate being investigated. Of the matrix proteins detected in MSC-CM by MALDI-TOF/TOF mass spectrometry, fibronectin was observed to have a profound effect upon cell adherence, similar to those findings concerning cell migration.

Individually, fibronectin appears contribute to the MSC-CM effects observed. However, the addition of MSC-CM to endothelial cell scratch assays performed upon fibronectin coated culture plates resulted in a further enhancement of endothelial cell migration, suggesting that fibronectin may not be solely responsible for the entire effect. Further experiments investigating the effects of MSC secreted growth factors and cytokines individually, and in combination, may reveal their relative contribution to the enhancement of endothelial cell migration. The relatively low number of individual donors examined during this study is a clear limitation, and although the results presented support the conclusions that (i) MSC donor variation and secretome composition may account for differential effects of MSCs on endothelial cells, and (ii) that this variation should be taken into consideration in MSC-based regenerative medicine, subsequent investigation of greater numbers of samples is required to further authenticate these findings.

\section{Conclusion}

Angiogenesis depends on endothelial cell migration and the actions of endothelial cell chemotactic factors, e.g. VEGF and $\mathrm{IL}-8^{[25-26]}$, and ECM proteins such as collagens, fibronectin and laminin ${ }^{[15]}$. Many of these pro-angiogenic factors have been found to be present within the MSC secretome both within this investigation and in previous studies $^{[5]}$. These experiments have showed that MSC-CM enhances both the rate of endothelial cell migration and the adherence of these cells to their culture surface, and that this effect was, in part, mediated by the presence of fibronectin. Other studies have also highlighted a role for fibronectin in stimulating angiogenesis ${ }^{[16,17]}$. The effects of MSC-CM upon endothelial cell migration were not entirely induced by fibronectin, as suggested by the further enhancement of EaHy-926 endothelial cell migration by MSC-CM in the presence of exogenous fibronectin. Factors such as Interleukin (IL)-8, VEGF, and laminin have all been shown to be stimulatory to endothelial cells ${ }^{[19,24]}$ and these factors have been shown to be present within MSC-CM ${ }^{[7]}$. It seems likely that these known mediators of angiogenesis might contribute to the effects of MSC-CM upon EaHy926 endothelial cells observed in these investigations.

Overall, the data presented here support the hypothesis that MSC may stimulate the formation of new vasculature, and that this may be an important aspect of MSC-mediated enhancement of wound healing.

\section{References}

1. Laschke MW, Harder $\mathrm{Y}$, Amon M, Martin I, Farhadi J, Ring A, Torio-Padron N, Schramm R, Rücker M, Junker D, Häufel JM, Carvalho C, Heberer M, Germann G, Vollmar $B$, Menger MD. Angiogenesis in tissue engineering: breathing life into constructed tissue substitutes. Tissue Eng 2006;12(8):2093-104.

2. Salem HK, Thiemermann C. Mesenchymal stromal cells: current understanding and clinical status. Stem Cells 2010;28(3):585-96.

3. Centeno CJ, Schultz JR, Cheever M, Robinson B, Freeman M, Marasco W. Safety and complications reporting on the re-implantation of culture-expanded mesenchymal stem cells using autologous platelet lysate technique. Curr Stem Cell Res Ther 2010;5(1):81-93.

4. Tarte K, Gaillard J, Lataillade JJ, Fouillard L, Becker M, Mossafa H, Tchirkov A, Rouard H, Henry C, Splingard M, Dulong J, Monnier D, Gourmelon P, Gorin NC, Sensebé L. Clinical-grade production of human mesenchymal stromal cells: Occurrence of aneuploidy without transformation. Blood 2010;115(8):1549-53.

5. Walter MNM, Wright KT, Fuller HR, MacNeil S, Johnson WEB. Mesenchymal stem cell-conditioned medium accelerates skin wound healing: An in vitro study of fibroblast and keratinocyte scratch assays. Exp Cell Res 2010;316(7):1271-81.

6. Kinnaird T, Burnett ES, Shou M, Lee CW, Barr S, Fuchs S, Epstein SE. Local Delivery of Marrow-Derived Stromal Cells Augments Collateral Perfusion Through Paracrine Mechanisms. Circulation 2004;109(12):1543-9.

7. Beckermann BM, Kallifatidis $G$, Groth $A$, Frommhold $D$, Apel A, Mattern J, Salnikov A V, Moldenhauer G, Wagner W, Diehlmann A, Saffrich R, Schubert M, Ho AD, Giese N, Büchler MW, Friess H, Büchler P, Herr I. VEGF expression by mesenchymal stem cells contributes to angiogenesis in pancreatic carcinoma. Br J Cancer 2008;99 (4):622-31. 
8. Oswald J, Boxberger S, Jørgensen B, Feldmann S, Ehninger G, Bornhäuser M, Werner C. Mesenchymal stem cells can be differentiated into endothelial cells in vitro. Stem Cells 2004;22(3):377-84.

9. Jazayeri M, Allameh A, Soleimani M, Jazayeri SH, Piryaei A, Kazemnejad S. Molecular and ultrastructural characterization of endothelial cells differentiated from human bone marrow mesenchymal stem cells. Cell Biol Int 2008;32(10):1183-92.

10. Iba O, Matsubara H, Nozawa $\mathrm{Y}$, Fujiyama S, Amano K, Mori $\mathrm{Y}$, Kojima $\mathrm{H}$, Iwasaka $\mathrm{T}$. Angiogenesis by implantation of peripheral blood mononuclear cells and platelets into ischemic limbs. Circulation 2002;106(15):2019-25.

11. Tomita S, Mickle DAG, Weisel RD, Jia ZQ, Tumiati LC, Allidina Y, Liu P, Li RK. Improved heart function with myogenesis and angiogenesis after autologous porcine bone marrow stromal cell transplantation. J Thorac Cardiovasc Surg 2002;123(6):1132-40.

12. Edgell CJ, McDonald CC, Graham JB. Permanent cell line expressing human factor VIII-related antigen established by hybridization. Proc Natl Acad Sci U S A 1983;80(12):3734-7.

13. Wright KT, Masri W El, Osman A, Roberts S, Trivedi J, Ashton BA, Johnson WEB. The cell culture expansion of bone marrow stromal cells from humans with spinal cord injury: implications for future cell transplantation therapy. Spinal Cord 2008;1246(12):811-7.

14. Dominici M, Blanc K Le, Mueller I, Slaper-Cortenbach I, Marini $F$, Krause D, Deans R, Keating a, Prockop D, Horwitz E. Minimal criteria for defining multipotent mesenchymal stromal cells. The International Society for Cellular Therapy position statement. Cytotherapy 2006;4(8):315-7.

15. Lu ZJ, Ren YQ, Wang GP, Song Q, Li M, Jiang SS, Ning T, Guan YS, Yang JL, Luo F. Biological behaviours and proteomics analysis of hybrid cell line EAhy926 and its parent cell line A549. J Exp Clin Cancer Res 2009;28:16.

16. Campbell NE, Kellenberger L, Greenaway J, Moorehead RA, Linnerth-Petrik NM, Petrik J. Extracellular matrix proteins and tumor angiogenesis. $\mathrm{J}$ Oncol 2010;2010:586905.
17. Yang JT, Rayburn H, Hynes RO. Embryonic mesodermal defects in alpha 5 integrin-deficient mice. Development 1993;119(4):1093-105.

18. Francis SE, Goh KL, Hodivala-Dilke K, Bader BL, Stark M, Davidson D, Hynes RO. Central roles of alpha5beta1 integrin and fibronectin in vascular development in mouse embryos and embryoid bodies. Arterioscler Thromb Vasc Biol 2002;22(6):927-33.

19. Marcinkiewicz C, Weinreb PH, Calvete JJ, Kisiel DG, Mousa SA, Tuszynski GP, Lobb RR. Obtustatin: a potent selective inhibitor of alpha1beta1 integrin in vitro and angiogenesis in vivo. Cancer Res 2003;63(9):2020-3.

20. Malinda KM, Nomizu M, Chung M, Delgado M, Kuratom Y, Yamada Y, Kleinman HK, Ponce ML. Identification of laminin alpha1 and beta1 chain peptides active for endothelial cell adhesion, tube formation, and aortic sprouting. FASEB J 1999;13(1):53-62.

21. Davies C de L, Melder RJ, Munn LL, Mouta-Carreira C, Jain RK, Boucher Y. Decorin inhibits endothelial migration and tube-like structure formation: role of thrombospondin1. Microvasc Res 2001;62(1):26-42.

22. Sulochana KN, Fan H, Jois S, Subramanian V, Sun F, Kini RM, Ge R. Peptides derived from human decorin leucinerich repeat 5 inhibit angiogenesis. J Biol Chem 2005;280(30):27935-48.

23. Niewiarowska J, Brézillon S, Sacewicz-Hofman I, Bednarek R, Maquart FX, Malinowski M, Wiktorska M, Wegrowski Y, Cierniewski CS. Lumican inhibits angiogenesis by interfering with $\alpha 2 \beta 1$ receptor activity and downregulating MMP-14 expression. Thromb Res 2011;128(5):452-7.

24. Albig AR, Roy TG, Becenti DJ, Schiemann WP. Transcriptome analysis of endothelial cell gene expression induced by growth on matrigel matrices: Identification and characterization of MAGP-2 and lumican as novel regulators of angiogenesis. Angiogenesis 2007;10(3):197216.

25. Ferrara N. VEGF-A: A critical regulator of blood vessel growth. Eur Cytokine Netw 2009;20(4):158-63.

26. Folkman J, Shing Y. Angiogenesis. J Biol Chem 1992;267(16):10931-4.

\section{Abbreviations}

$\begin{array}{ll}\text { CD: } & \text { Cluster of Differentiation } \\ \text { COMP: } & \text { Cartilage Oligomeric Matrix Protein } \\ \text { DMEM: } & \text { Dulbecco's modified Eagle's Medium } \\ \text { ECM: } & \text { Extracellular Matrix } \\ \text { FCS: } & \text { Fetal Calf Serum } \\ \text { HSPG: } & \text { Heparan Sulphate Proteoglycan } \\ \text { IGFBP: } & \text { Insulin-like Growth Factor Binding Protein } \\ \text { IL: } & \text { Interleukin } \\ \text { ISCT: } & \text { International Society for Cellular Therapy } \\ \text { MALDI-TOF/TOF: } & \text { Matrix-Assisted Laser Desorption/lonization-Time Of Flight/Time Of Flight } \\ \text { MSC: } & \text { Mesenchymal Stem Cell } \\ \text { MSC-CM: } & \text { Mesenchymal Stem Cell-Conditioned Medium } \\ \text { PBS: } & \text { Phosphate Buffered Saline } \\ \text { SEM: } & \text { Standard Error of the Mean } \\ \text { SPARC: } & \text { Secreted Protein, Acidic and Rich in Cysteine } \\ \text { VEGF: } & \text { Vascular Endothelial Growth Factor }\end{array}$




\section{Potential Conflicts of Interests}

None

\section{Sponsors/Grants}

This study was funded by the Biotechnology and Biological Sciences Research Council. BBSRC, Polaris House, North Star Avenue, Swindon, SN2 1UH, UK. Tel: +44 1793413200.

\section{Corresponding Author}

Dr. Merlin N M Walter PhD, Institute for Genetic Medicine, Centre for Life, Newcastle upon Tyne, Tyne and Wear, UK, NE1 4EP. Tel: 07581579411; Email: merlin.walter@ncl.ac.uk ; Alt email: m.n.m.walter@reading.ac.uk 